Communi cat i on: Coor di nat $i$ on st ruct ure of brom de i ons associ at ed wi th

hexyl tri met hyl ammoni um cat $i$ ons at

$\mathrm{I}$ i qui $d / \mathrm{l}$ i qui $d$ interfaces under potent i ost at i $\mathrm{c}$ control as studi ed by total-reflecti on X-ray absorpti on fine structure

\begin{tabular}{|l|l|}
\hline 著者 & $\begin{array}{l}\text { Nagat ani H r ohi sa, Har ada Nakot o, Tani da } \\
\text { Haj i me, Sakae Hi roki, I mur a H sanor i }\end{array}$ \\
\hline $\begin{array}{l}\text { j our nal or } \\
\text { publ i cat i on ti t l e }\end{array}$ & Journal of Chem cal Physi cs \\
\hline vol une & 140 \\
\hline number & 10 \\
\hline page r ange & 101101 \\
\hline year & 2014 03 14 \\
\hline URL & ht t p: //hdl . handl e. net /2297/37537 \\
\hline
\end{tabular}




\title{
Communication: Coordination structure of bromide ions associated with hexyltrimethylammonium cations at liquid/liquid interfaces under potentiostatic control as studied by total-reflection X-ray absorption fine structure
}

\author{
Hirohisa Nagatani, ${ }^{1}$, a) Makoto Harada, ${ }^{2}$ Hajime Tanida, $\left.{ }^{3, b}\right)$ Hiroki Sakae, ${ }^{4}$ \\ and Hisanori Imura ${ }^{1}$ \\ ${ }^{1}$ Faculty of Chemistry, Institute of Science and Engineering, Kanazawa University, Kakuma, \\ Kanazawa 920-1192, Japan \\ ${ }^{2}$ Department of Chemistry, Graduate School of Science and Engineering, Tokyo Institute of Technology, \\ Meguro, Tokyo 152-8551, Japan \\ ${ }^{3}$ Materials Science Division, Japan Synchrotron Radiation Research Institute, Sayo, Hyogo 679-5198, Japan \\ ${ }^{4}$ Division of Material Sciences, Graduate School of Natural Science and Technology, Kanazawa University, \\ Kakuma, Kanazawa 920-1192, Japan
}

(Received 4 February 2014; accepted 25 February 2014; published online 10 March 2014)

\begin{abstract}
Total-reflection X-ray absorption fine structure (TR-XAFS) technique was applied for the first time to an interface between two immiscible electrolyte solutions under potentiostatic control. The hydration structure of bromide ions was investigated at polarized 2-octanone/water interfaces. TR-XAFS spectra at $\mathrm{Br} \mathrm{K}$-edge measured in the presence of hexyltrimethylammonium bromide $\left(\mathrm{C}_{6} \mathrm{TAB}\right)$ were slightly modified depending on the Galvani potential difference $\left(\Delta_{\mathrm{o}}^{\mathrm{w}} \phi\right)$. The extended $\mathrm{X}$-ray absorption fine structure analysis exposed hydration structure changes of bromide ions at the polarized interface. The coordination structure of bromide ions at the interface could be analyzed as compared with bromide ions dissolved in aqueous solution and $\mathrm{Br}^{-}$-exchanged resin having quaternary ammonium groups. The results indicated that bromide ions were associated with $\mathrm{C}_{6} \mathrm{TA}^{+}$ at the polarized interface. The relative contribution of ion association form of bromide ions with quaternary ammonium groups was enhanced at a potential close to the ion transfer of $\mathrm{C}_{6} \mathrm{TA}^{+}$, where the interfacial concentration of $\mathrm{C}_{6} \mathrm{TA}^{+}$is increased as a function of $\Delta_{0}^{\mathrm{w}} \phi$. () 2014 AIP Publishing LLC. [http://dx.doi.org/10.1063/1.4867899]
\end{abstract}

An interface between two immiscible solutions (ITIES) is a two-dimensional specific reaction field. The interfacial reactions have been extensively studied for separation sciences, synthesis of thin-layer materials, and biochemical applications. ${ }^{1}$ Under potentiostatic conditions, the charge transfer reaction across the interface can be controlled as a function of the applied potential. ${ }^{2}$ The interfacial reaction often involves adsorption processes of reactants and specific species formed only at the interface. ${ }^{3}$ The characterization of interfacial species at the molecular level is thus essential to elucidate the heterogeneous reaction mechanism. The structural analysis such as a solvation structure has, however, rarely been carried out in situ at ITIES because of the lack of a suitable technique.

$\mathrm{X}$-ray absorption fine structure (XAFS) is widely used to analyze the molecular structure in various chemical states. Total-reflection XAFS (TR-XAFS) techniques have been applied mainly for thin-layer materials and surface species on chemically modified solid surfaces. In order to characterize the species at soft interfaces, ${ }^{4}$ whose concentration is

\footnotetext{
a) Author to whom correspondence should be addressed. Electronic mail: nagatani@se.kanazawa-u.ac.jp

b) Present address: Office of Society-Academia Collaboration for Innovation, Kyoto University, Uji, Kyoto 611-0011, Japan.
}

much lower than that of solid surface systems, the TR-XAFS method should be combined with highly sensitive detection techniques such as a total-conversion helium ion yield mode ${ }^{5}$ or a fluorescence yield mode. ${ }^{6}$ The polarization dependences of TR-XAFS spectrum have also provided valuable insights into the molecular orientation and coordination structure of metal complexes at soft interfaces. ${ }^{7-9}$ Recently, the polarized TR-XAFS method was applied to liquid/liquid interfaces, in which a partial dehydration of the axial sites of anionic zinc(II) porphyrin spontaneously adsorbed at the heptane/water interface was directly observed from the polarization dependences of X-ray absorption near-edge structure (XANES) involving a $1 \mathrm{~s}-4 \mathrm{p}_{\mathrm{z}}$ transition for a square planar metal complex. ${ }^{10}$ The interfacial association between alkylammonium surfactants and bromide ions was also measured at the heptane/water interface. ${ }^{11,12}$

In the present study, the TR-XAFS technique was applied for the first time to the liquid/liquid interface under potentiostatic control. The electrochemical studies at ITIES have mostly been carried out by means of the water/1,2dichloroethane (DCE) and water/nitrobenzene (NB) systems. In those systems, valuable electrochemical parameters such as standard transfer potential correlated to the Gibbs free energy of transfer and partition coefficient are available for a variety of ionic species. Schlossman and co-workers have 
studied the ion condensation and distribution properties of monovalent ions at electrified water/DCE interfaces by X-ray reflectivity analysis, in which the incident X-ray at $\sim 30 \mathrm{keV}$ was introduced to the interface through an upper aqueous phase. ${ }^{13-15}$ For X-ray absorption spectroscopy, however, the incident X-ray introduced to the interfacial region, whose energy is restricted by the absorption edge of a target atom and much smaller (e.g., $13.5 \mathrm{keV}$ for the Br K-edge) than that for X-ray reflectivity, is considerably attenuated by an upper solution phase. For instance, the attenuation lengths of $\mathrm{X}$-ray at $13.5 \mathrm{keV}$ for water, DCE and NB are calculated as 4.9, 0.48, and $6.4 \mathrm{~mm}$, respectively. ${ }^{16}$ The 2-octanone/water and 2-heptanone/water interfaces have been developed for ITIESs with low toxicity. ${ }^{17,18}$ In particular, 2-octanone provides a wider polarizable potential window compared with 2-heptanone. A longer attenuation length (i.e., $12 \mathrm{~mm}$ at $13.5 \mathrm{keV}$ ) is also suitable for the XAFS study. The TR-XAFS experiments were thus performed at the 2-octanone/water interface. The composition of electrochemical cell and the TR-XAFS cell are schematically shown in Fig. 1. The supporting electrolytes were $2 \times 10^{-3} \mathrm{~mol} \mathrm{dm}^{-3}$ bis(triphenylphosphoranylidene)ammonium tetrakis(pentafluorophenyl) borate (BTPPATPFB) for the upper organic phase and $2 \times 10^{-3} \mathrm{~mol} \mathrm{dm}^{-3}$ sodium bromide for the aqueous subphase, respectively. BTPPATPFB was prepared by metathesis of bis(triphenylphosphoranylidene)ammonium chloride (BTPPACl) (Aldrich, >97\%) and lithium tetrakis(pentafluorophenyl)borate (LiTPFB) ethyl ether complex (TCI, $\geq 70 \%)$. Hexyltrimethylammonium bromide $\left(\mathrm{C}_{6} \mathrm{TAB}\right)$ and 2-octanone were of GR grade (TCI, >98\%). All other reagents were of analytical grade. The aqueous solutions were prepared with purified water from a Milli-Q system (Millipore, Simpli Lab-UV). The 2-octanone/water interface was polarized by a four-electrode potentiostat equipped with a positive feedback circuit for $i R$ compensation (Hokuto Denko, HA1010mM1A). The platinum counter (CE) and reference electrodes (RE: Ag/AgTPFB with a Luggin capillary and $\mathrm{Ag} / \mathrm{AgBr}$ ) in both organic and aqueous phases were placed not on the optical path. The TR-XAFS measurement was performed at the undulator beamline BL39XU of SPring-8 (Hyogo, Japan). The TR-XAFS cell was made of polychlorotrifluoroethylene resin (PCTFE). The incident $\mathrm{X}$-ray beam $(0.020 \mathrm{~mm}$ (height) $\times 2.0 \mathrm{~mm}$ (width) $)$ was introduced to the interface through the upper organic phase under the total-reflection condition. The critical angle for the 2-octanone/water system is $\sim 0.66 \mathrm{mrad}$ at $\mathrm{Br} \mathrm{K}$-edge and the angle of incidence $\left(\alpha_{\mathrm{i}}\right)$ was $0.49 \leq \alpha_{\mathrm{i}} \leq 0.51 \mathrm{mrad}$ in all measurements. The footprint of X-rays at the 2-octanone/water interface was calculated as $40 \mathrm{~mm} \times 2 \mathrm{~mm}$ at $\alpha_{\mathrm{i}}=0.50 \mathrm{mrad}$. The fluorescent X-ray from the interfacial region was detected by a seven-element silicon drift detector (SDD) (Ourstex). A Se filter (Exafs Materials, $\mu \mathrm{t}=6$ at $\mathrm{Br} \mathrm{K}$-edge) was used in order to reduce the background scattering. The detector window was in close proximity to the interface $(<2 \mathrm{~mm})$ so as to minimize the attenuation of the fluorescent signal through the organic phase. The cell windows for the incident $\mathrm{X}$-ray and the detector were $0.038 \mathrm{~mm}$ thick polyimide (Kapton) film and $0.025 \mathrm{~mm}$ thick fluorinated ethylene propylene (FEP) film, respectively. A quartz frame with only the top (a)

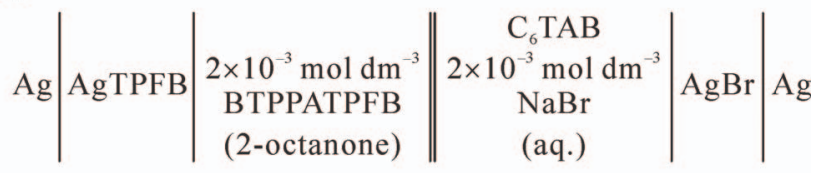

(b)

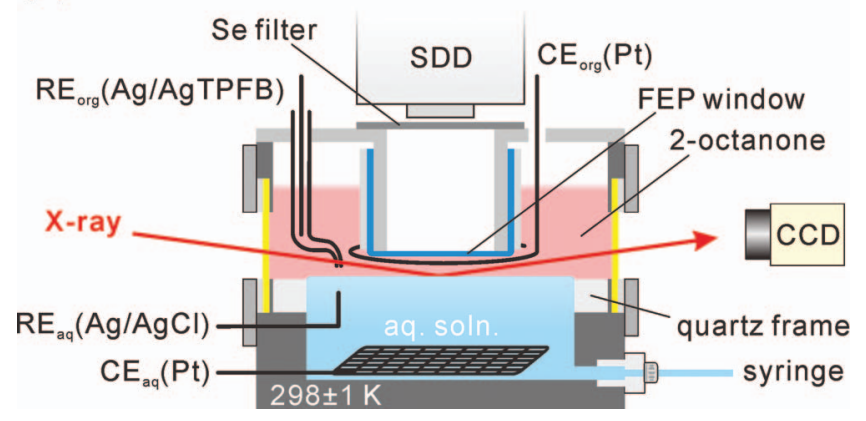

FIG. 1. (a) Composition of the electrochemical cell and (b) schematic drawing of the TR-XAFS cell.

face coated with hydrophobic dimethylsilane was placed in between two phases to form a flat-top convex meniscus. A flatness of the interface $(60 \mathrm{~mm} \times 40 \mathrm{~mm})$ was controlled by expanding the aqueous solution volume with a syringe pump. The reflected X-ray beam was continuously monitored by a CCD camera in order to confirm the total-reflection condition. The TR-XAFS cell was thermostated at $298 \pm 1 \mathrm{~K}$.

Cyclic voltammograms (CVs) at the 2-octanone/ water interface are displayed in Fig. 2. The Galvani potential difference $\left(\Delta_{\mathrm{o}}^{\mathrm{w}} \phi \equiv \phi^{\mathrm{w}}-\phi^{\mathrm{o}}\right)$ was estimated by taking a value of $-0.01 \mathrm{~V}$ for the formal transfer potential $\left(\Delta_{\mathrm{o}}^{\mathrm{w}} \phi^{\circ}\right)$ of tetrapropylammonium $\left(\mathrm{TPA}^{+}\right) .{ }^{17}$ The present electrochemical cell provided a polarizable potential window of $\sim 0.38 \mathrm{~V}$ width $\left(-0.28 \mathrm{~V} \leq \Delta_{\mathrm{o}}^{\mathrm{w}} \phi \leq 0.10 \mathrm{~V}\right)$ (Fig. S1 in the supplementary material). ${ }^{19}$ The positive and negative limits of the potential window could be attributed, respectively, to the transfer of $\mathrm{TPFB}^{-}$and $\mathrm{BTPPA}^{+}$across the interface. The quasi-reversible voltammetric responses with the peak separation of $\sim 60 \mathrm{mV}$ for a monovalent cation were observed for $\mathrm{C}_{6} \mathrm{TA}^{+}$by using a small conventional four-electrode cell with an interfacial area of $1.8 \mathrm{~cm}^{2}$ (Fig. 2(a)). The formal transfer potential of $\mathrm{C}_{6} \mathrm{TA}^{+}$was determined as $\Delta_{\mathrm{o}}^{\mathrm{w}} \phi_{\mathrm{C}_{6} \mathrm{TA}^{+}}^{\circ}=0.02 \mathrm{~V}$. It should be noted that the total concentration of $\mathrm{C}_{6} \mathrm{TAB}$ in the aqueous subphase was less than $1 \times 10^{-3} \mathrm{~mol} \mathrm{dm}^{-3}$, which is much lower than the critical micelle concentration (CMC), $0.495 \mathrm{~mol} \mathrm{dm}^{-3} \cdot{ }^{20}$ In the case of the TR-XAFS cell, the ion transfer current drastically increased because of the large interfacial area $\left(24 \mathrm{~cm}^{2}\right)$ (Fig. 2(b)). The potentiostatic condition for TR-XAFS measurements with a stable $i R$ compensation was therefore restricted to $\Delta_{\mathrm{o}}^{\mathrm{w}} \phi<0 \mathrm{~V}$ by the transfer of $\mathrm{C}_{6} \mathrm{TA}^{+}$. In addition, the CVs exhibit a significant increase in the capacitive current at negative potentials associated with the adsorption of $\mathrm{C}_{6} \mathrm{TA}^{+}$at the interface. $\mathrm{C}_{6} \mathrm{TAB}$ is known to act as a surfactant and form the ion-associate with anionic species at liquid/liquid interfaces. ${ }^{10}$

The TR-XAFS spectra at the $\mathrm{Br} \mathrm{K}$-edge were successfully obtained at polarized 2-octanone/water interfaces 

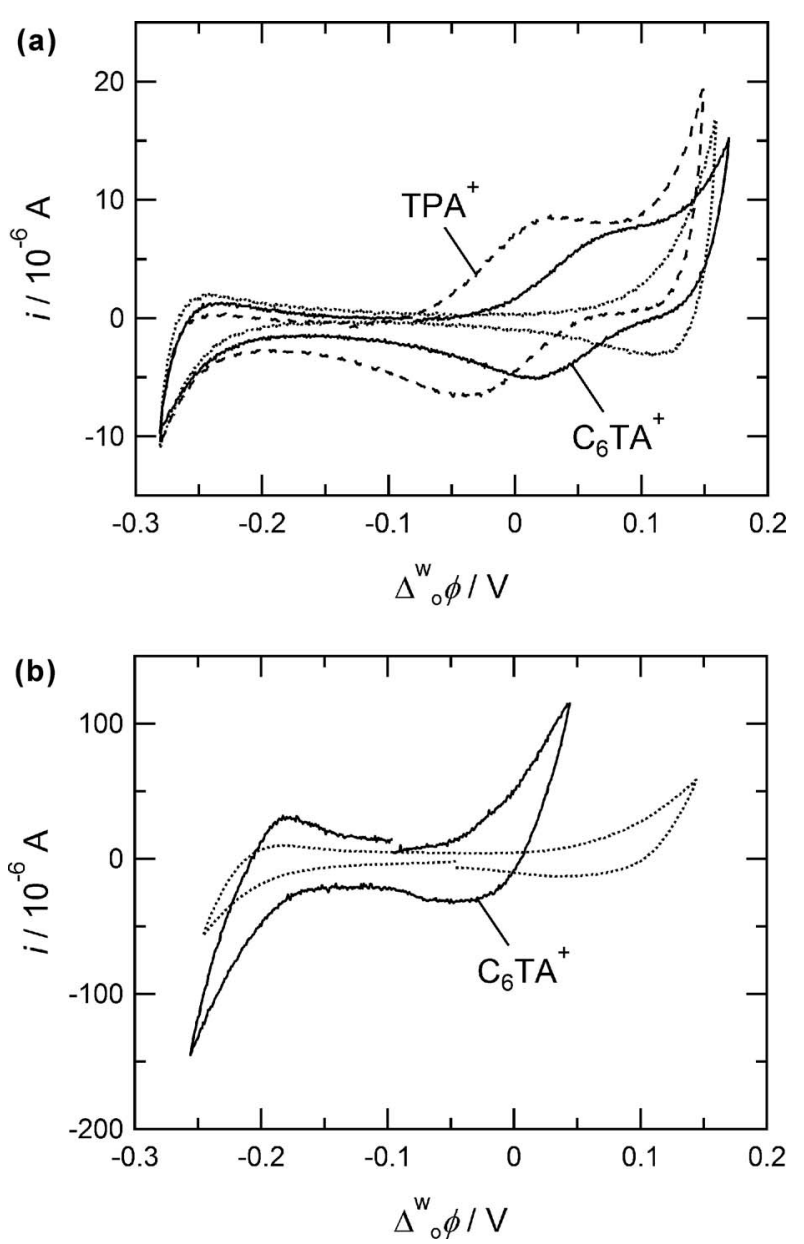

FIG. 2. Typical CVs measured for (a) $1.0 \times 10^{-4} \mathrm{~mol} \mathrm{dm}^{-3} \mathrm{C}_{6} \mathrm{TA}^{+}$and $\mathrm{TPA}^{+}$(small cell) and (b) $1.0 \times 10^{-3} \mathrm{~mol} \mathrm{dm}^{-3} \mathrm{C}_{6} \mathrm{TA}^{+}$(TR-XAFS cell) at the 2-octanone/water interface. The dotted lines refer to CVs in the absence of alkylammonium cations. The potential sweep rate was $10 \mathrm{mV} \mathrm{s}^{-1}$.

(Fig. 3). The standard Gibbs free energy of ion transfer $\left(\Delta G_{\mathrm{tr}}^{\mathrm{w} \rightarrow \mathrm{o}}\right)$ for bromide ions was reported as $40.1 \mathrm{~kJ} \mathrm{~mol}^{-1}$, which corresponds to $\Delta_{\mathrm{o}}^{\mathrm{w}} \phi_{\mathrm{Br}^{-}}^{\circ}=-0.42 \mathrm{~V}{ }^{17}$ The large negative value of $\Delta_{\mathrm{o}}^{\mathrm{w}} \phi_{\mathrm{Br}^{-}}^{\circ}$ indicates that the bromide ions are not transferred across the 2-octanone/water interface within the potential window. Indeed, when the X-ray beam did not irradiate the interface and passed through the upper organic phase at $\sim 1 \mathrm{~mm}$ from the interface, the fluorescence intensity dropped drastically to a negligibly small value. The TR-XAFS spectra thus reflect the bromide ions located in an evanescent field generated at the aqueous side of the interface, e.g., the penetration depth is calculated as $\sim 17 \mathrm{~nm}$ $\left(\alpha_{\mathrm{i}}=0.50 \mathrm{mrad}\right)$. The XANES spectra observed at both $-0.03 \mathrm{~V}$ and $-0.17 \mathrm{~V}$ were analogous to the spectra measured at the neat interface in the absence of $\mathrm{C}_{6}$ TAB (Fig. 3(a)), indicating no drastic differences in the coordination structure of bromide ions at the interface in the presence of $\mathrm{C}_{6} \mathrm{TA}^{+}$. Nevertheless, the signal-to-noise level of the fluorescence $\mathrm{X}$ ray signals from the interfacial region was apparently improved in the presence of $\mathrm{C}_{6} \mathrm{TAB}$. On the other hand, the EXAFS analysis highlighted the buried changes in the TR-XAFS spectra as a function of $\Delta_{\mathrm{o}}^{\mathrm{w}} \phi$, i.e., the significant phase shift of $k^{3} \chi(k)$ data was observed at $k>3 \AA^{-1}$ (Fig. S2(a) in the supplementary material). ${ }^{19}$ XAFS spectrum was analyzed by
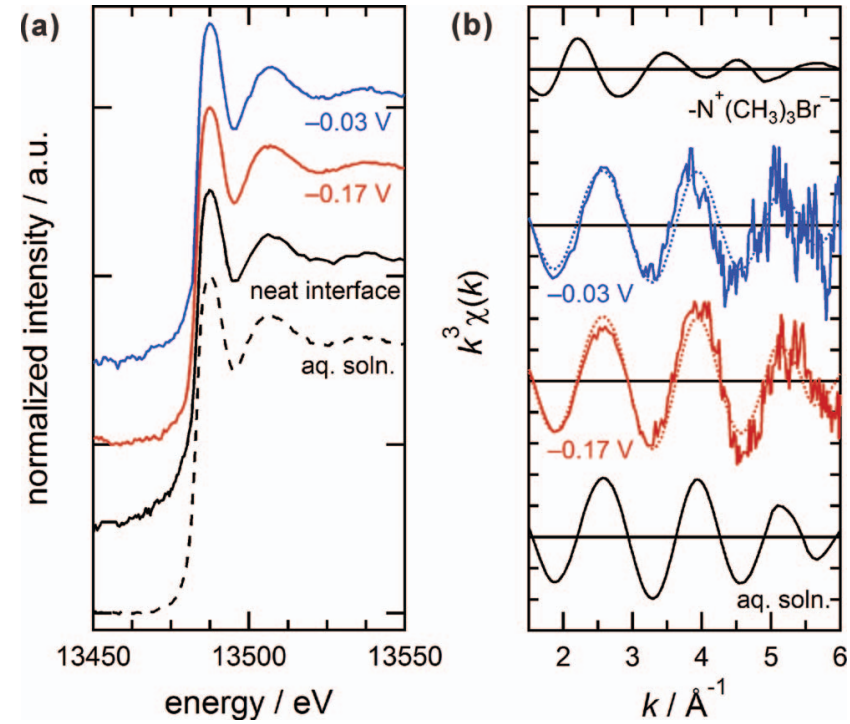

FIG. 3. (a) TR-XAFS and (b) $k^{3} \chi(k)$ spectra for Br K-edge measured at polarized 2-octanone/water interfaces $\left(\Delta_{\mathrm{o}}^{\mathrm{w}} \phi=-0.03 \mathrm{~V}\right.$ and $\left.-0.17 \mathrm{~V}\right)$. (a) The black solid and dashed lines refer to the neat interface without adding $\mathrm{C}_{6} \mathrm{TAB}$ and $2 \times 10^{-3} \mathrm{~mol} \mathrm{dm}{ }^{-3} \mathrm{NaBr}$ in water. (b) The dotted lines refer to the fitting-curves obtained from the linear combination of $k^{3} \chi(k)$ spectra for $\mathrm{Br}^{-}$-exchanged resin powder (Amberlyst A-26) and $1 \mathrm{~mol} \mathrm{dm}^{-3} \mathrm{LiBr}$ aqueous solution measured in transmission mode.

a curve-fitting based on a single-shell model with $\mathrm{Br} \cdot \cdots \mathrm{HO}$ parameters calculated with FEFF ver. 8.2, where the $\mathrm{O} \cdots \mathrm{H}$ distance was fixed as $0.95 \AA$ (Fig. S2(b) in the supplementary material). ${ }^{19}$ As summarized in Table I, the structural parameters for $\mathrm{Br}^{-}$at the interface were apparently modified from the hydrated bromide ion in water $(N=6.0$ and $r=3.25 \AA)$. The relative coordination number $\left(N^{\prime}\right)$ with respect to the hexahydrated form in water and $\mathrm{Br} \cdots \mathrm{O}$ distance $(r / \AA)$ were 3.8 and $3.32 \AA$ at $-0.03 \mathrm{~V}$, whereas 4.3 and $3.17 \AA$ at $-0.17 \mathrm{~V}$. The $r$ values were analogous to that of the aqueous species $(3.25 \AA)$ within experimental error. The smaller $N^{\prime}$ values might correspond to the partial dehydration of bromide ions associated with $-\mathrm{N}^{+}\left(\mathrm{CH}_{3}\right)_{3}$ groups at the interface. The EXAFS $R$-factors $(>0.2)$ for the quality of fit, however, indicate that the single-shell $\mathrm{Br}$. OO structure is not successfully adapted to the structural analysis for the interfacial species. In the present condition, two-possible coordination structures could be proposed for the bromide ions in the interfacial region: hexahydrated form in similar to aqueous species and ion association form with $\mathrm{C}_{6} \mathrm{TA}^{+}{ }^{21}$ In order to estimate the contribution from two-possible structures, the $k^{3} \chi(k)$ data measured at the polarized interface were decomposed by the regression analysis with the linear combination of $k^{3} \chi(k)$ spectra for hexahydrated bromide ions in water and the $\mathrm{Br}^{-}-$ exchanged resin (powder): ${ }^{22,23}$

$$
\chi_{\mathrm{obs}}=\alpha \chi_{\mathrm{hyd}}+\beta \chi_{\mathrm{resin}},
$$

where $\chi_{\text {obs }}, \chi_{\text {hyd }}$, and $\chi_{\text {resin }}$ are the $\chi$ spectra measured for the interface at given potentials, for $1 \mathrm{~mol} \mathrm{dm}^{-3} \mathrm{LiBr}$ aqueous solution and for $\mathrm{Br}^{-}$-exchanged quaternary-ammonium resin having $-\mathrm{N}^{+}\left(\mathrm{CH}_{3}\right)_{3}$ groups (Amberlyst A-26, Rohm and Hass) (Fig. 3(b)), respectively, measured in transmission mode. The proportional factors $\alpha$ and $\beta$ refer to the contributions from $\chi_{\text {hyd }}$ and $\chi_{\text {resin. }}$. It was reported that $-\mathrm{N}^{+}\left(\mathrm{CH}_{3}\right)_{3}$ 
TABLE I. Structural parameters based on the single-shell model and regression analysis with Eq.(1) for bromide ions associated with hexyltrimethylammonium cations at polarized 2-octanone/water interfaces.

\begin{tabular}{|c|c|c|c|c|}
\hline & \multicolumn{2}{|c|}{ 2-octanone/water interface ${ }^{\mathrm{a}}$} & \multirow[b]{2}{*}{ Hydrated $\mathrm{Br}^{-}\left(1 \mathrm{~mol} \mathrm{dm}^{-3} \mathrm{LiBr}\right)^{\mathrm{b}}$} & \multirow[b]{2}{*}{$\mathrm{Br}^{-}$-exchanged resin (powder) $)^{\mathrm{b}, \mathrm{c}}$} \\
\hline & $-0.03 \mathrm{~V}$ & $-0.17 \mathrm{~V}$ & & \\
\hline$r / \AA$ & 3.32 & 3.17 & 3.25 & 3.53 \\
\hline$N^{\prime \mathrm{d}}$ & 3.8 & 4.3 & 6 & 4.27 \\
\hline$\sigma / \AA^{\mathrm{e}}$ & 0.15 & 0.14 & 0.18 & 0.20 \\
\hline$R$-factor & 0.241 & 0.202 & 0.019 & \\
\hline$\overline{\alpha: \beta^{\mathrm{f}}}$ & $88: 12$ & $94: 6$ & & \\
\hline
\end{tabular}

groups preferentially interact with bromide ions in the anion exchange resin, ${ }^{22}$ whereas the coordination structure of the bromide ions in dried tetraalkylammonium bromide powder includes the contribution of not only $-\mathrm{N}^{+}\left(\mathrm{CH}_{3}\right)_{3}$ groups but also other neighboring molecules. ${ }^{24,25}$ The $k^{3} \chi(k)$ data for the $\mathrm{Br}^{-}$-exchanged resin as a component is, therefore, appropriate to estimate the contribution of ion association between bromide ions and $-\mathrm{N}^{+}\left(\mathrm{CH}_{3}\right)_{3}$ groups. The $N^{\prime}$ and $r$ values for the $\mathrm{Br}^{-}$-exchanged resin were reported as 4.27 and $3.53 \AA$, respectively. ${ }^{22}$ The relative contributions to the interfacial spectrum from two components $(\alpha: \beta)$ were calculated as 88:12 $(R$-factor $=0.060)$ at $-0.03 \mathrm{~V}$ and $94: 6(R$-factor $=0.040)$ at $-0.17 \mathrm{~V}$, respectively. The results indicate that the coordination structure of bromide ions in the interfacial region was slightly modified from the bulk aqueous species. The ion association with quaternary-ammonium seems to be enhanced at the potential close to $\Delta_{\mathrm{o}}^{\mathrm{w}} \phi_{\mathrm{C}_{6} \mathrm{TA}^{+}}^{\prime}$. The interfacial concentration of surface active ions is generally controlled as a function of $\Delta_{\mathrm{o}}^{\mathrm{w}} \phi$ and maximized at its transfer potential, ${ }^{26,27}$ hence a higher interfacial concentration of $\mathrm{C}_{6} \mathrm{TA}^{+}$at $-0.03 \mathrm{~V}$ could induce the effective interaction with bromide ions at the interface.

In this work, the TR-XAFS measurement of the coordination structure of bromide ions associated with hexyltrimethylammonium cations at ITIES was carried out under potentiostatic conditions by employing the custom-built spectroelectrochemical cell and relatively transparent organic solvent (2-octanone). The EXAFS analysis elucidated slight changes in the average coordination structure of bromide ions in the interfacial region depending on $\Delta_{\mathrm{o}}^{\mathrm{w}} \phi$. Although the application of the present setup to lower energy absorption edges includes some difficulties resulting from a considerable attenuation of the incident beam and fluorescence signal, the TR-XAFS technique is quite useful to characterize a specific coordination structure at ITIES.

The authors thank Dr. Naomi Kawamura, Dr. Masaichiro Mizumaki, and Dr. Motohiro Suzuki of the Japan Synchrotron Radiation Research Institute for their technical assistance. This work was supported by Grants-in-Aid for Scientific Research (B) (No. 21350047) and Scientific Research (C) (No.
24550097) from Japan Society for the Promotion of Science (JSPS). This work has been performed under the approval of SPring-8 (Nos. 2011B1045, 2012A1281, and 2012B1225).

${ }^{1}$ A. G. Volkov, Liquid Interfaces in Chemical, Biological, and Pharmaceutical Application (Marcel Dekker, New York, 2001).

${ }^{2}$ H. H. Girault, Electroanal. Chem. 23, 1 (2010).

${ }^{3} \mathrm{H}$. Watarai, N. Teramae, and T. Sawada, Interfacial Nanochemistry (Kluwer Academic/Plenum Publishers, New York, 2005).

${ }^{4}$ H. Tanida, Spectrochim. Acta B 59, 1071 (2004).

${ }^{5}$ I. Watanabe, H. Tanida, S. Kawauchi, M. Harada, and M. Nomura, Rev. Sci. Instrum. 68, 3307 (1997).

${ }^{6} \mathrm{H}$. Tanida and M. Ishii, Nucl. Instrum. Methods Phys. Res. A 467-468, 1564 (2001).

${ }^{7}$ H. Tanida, H. Nagatani, and I. Watanabe, J. Chem. Phys. 118, 10369 (2003).

${ }^{8}$ H. Nagatani, H. Tanida, T. Ozeki, and I. Watanabe, Langmuir 22, 209 (2006).

${ }^{9}$ H. Nagatani, H. Tanida, I. Watanabe, and T. Sagara, Anal. Sci. 25, 475 (2009).

${ }^{10}$ H. Nagatani, H. Tanida, M. Harada, M. Asada, and T. Sagara, J. Phys. Chem. C 114, 18583 (2010).

${ }^{11}$ H. Tanida, H. Nagatani, and M. Harada, J. Phys.: Conf. Ser. 83, 012019 (2007).

${ }^{12}$ H. Tanida, H. Nagatani, and M. Harada, J. Phys.: Conf. Ser. 190, 012061 (2009).

${ }^{13}$ B. Hou, N. Laanait, H. Yu, W. Bu, J. Yoon, B. Lin, M. Meron, G. Luo, P. Vanysek, and M. L. Schlossman, J. Phys. Chem. B 117, 5365 (2013).

${ }^{14}$ N. Laanait, M. Mihaylov, B. Hou, H. Yu, P. Vanýsek, M. Meron, B. Lin, I. Benjamin, and M. L. Schlossman, Porc. Natl. Acad. Sci. U.S.A. 109, 20326 (2012).

${ }^{15}$ N. Laanait, J. Yoon, B. Hou, P. Vanysek, M. Meron, B. Lin, G. Luo, I. Benjamin, and M. L. Schlossman, J. Chem. Phys. 132, 171101 (2010).

${ }^{16}$ B. L. Henke, E. M. Gullikson, and J. C. Davis, At. Data Nucl. Data Tables 54, 181 (1993).

${ }^{17}$ Y. Cheng and D. J. Schiffrin, J. Electroanal. Chem. 409, 9 (1996).

${ }^{18}$ Y. Cheng and D. J. Schiffrin, J. Electroanal. Chem. 429, 37 (1997).

${ }^{19}$ See supplementary material at http://dx.doi.org/10.1063/1.4867899 for the electrochemical data and the EXAFS analysis based on the single-shell model.

${ }^{20}$ V. Mosquera, J. M. Del Río, D. Attwood, M. García, M. N. Jones, G. Prieto, M. J. Suarez, and F. Sarmiento, J. Colloid Interface Sci. 206, 66 (1998).

${ }^{21}$ M. Harada, H. Satou, and T. Okada, J. Phys. Chem. B 111, 12136 (2007).

${ }^{22}$ M. Harada and T. Okada, J. Chromatogr A 1085, 3 (2005).

${ }^{23}$ T. Okada and M. Harada, Anal. Chem. 76, 4564 (2004).

${ }^{24}$ A. R. Campanelli and L. Scaramuzza, Acta Cryst. C42, 1380 (1986).

${ }^{25}$ S. Kamitori, Y. Sumimoto, K. Vongbupnimit, K. Noguchi, and K. Okuyama, Mol. Cryst. Liq. Cryst. 300, 31 (1997).

${ }^{26}$ H. Nagatani, D. J. Fermín, and H. H. Girault, J. Phys. Chem. B 105, 9463 (2001).

${ }^{27}$ T. Kakiuchi, J. Electroanal. Chem. 496, 137 (2001). 